\title{
Modelling Shallow Groundwater Evaporation Rates from a Large Tank Experiment
}

\author{
Nicolò Colombani ${ }^{1}$ - Davide Fronzi ${ }^{1}$. Stefano Palpacelli ${ }^{1}$ - Mattia Gaiolini ${ }^{1}$. \\ Maria Pia Gervasio $^{3} \cdot$ Mirco Marcellini $^{1} \cdot$ Micol Mastrocicco $^{2}$ (D) Alberto Tazioli $^{1}$
}

Received: 23 March 2021 / Accepted: 28 June 2021 / Published online: 9 July 2021

(C) The Author(s) 2021

\begin{abstract}
A large tank $(1.4 \mathrm{~m} \times 4.0 \mathrm{~m} \times 1.3 \mathrm{~m})$ filled with medium-coarse sand was employed to measure evaporation rates from shallow groundwater at controlled laboratory conditions, to determine drivers and mechanisms. To monitor the groundwater level drawdown 12 piezometers were installed in a semi regular grid and equipped with high precision water level, temperature, and electrical conductivity (EC) probes. In each piezometer, 6 micro sampling ports were installed every $10 \mathrm{~cm}$ to capture vertical salinity gradients. Moreover, the soil water content, temperature and EC were measured in the unsaturated zone using TDR probes placed at 5, 20 and $40 \mathrm{~cm}$ depth. The monitoring started in February 2020 and lasted for 4 months until the groundwater drawdown became residual. To model the groundwater heads, temperature, and salinity variations SEAWAT 4.0 was employed. The calibrated model was then used to obtain the unknown parameters, such as: maximum evaporation rates $(1.5-4.4 \mathrm{~mm} / \mathrm{d})$, extinction depth $(0.90 \mathrm{~m})$, mineral dissolution $\left(5.0 \mathrm{e}^{-9}\right.$ $\mathrm{g} / \mathrm{d})$ and evaporation concentration $(0.35 \mathrm{~g} / \mathrm{L})$. Despite the drawdown was uniformly distributed, the increase of groundwater salinity was rather uneven, while the temperature increase mimicked the atmospheric temperature increase. The initial groundwater salinity and the small changes in the evaporation rate controlled the evapoconcentration process in groundwater, while the effective porosity was the most sensitive parameter. This study demonstrates that shallow groundwater evaporation from sandy soils can produce homogeneous water table drawdown but appreciable differences in the distribution of groundwater salinity.
\end{abstract}

Keywords Continuous monitoring $\cdot$ Numerical model $\cdot$ Evaporation $\cdot$ Bare soil · Groundwater salinity

Micol Mastrocicco

micol.mastrocicco@unicampania.it

1 Department of Materials, SIMAU, Environmental Sciences and Urban Planning, Università Politecnica delle Marche, Via Brecce Bianche 12, 60131 Ancona, Italy

2 DiSTABiF - Department of Environmental, Biological and Pharmaceutical Sciences and Technologies, Campania University "Luigi Vanvitelli", Via Vivaldi 43, 81100 Caserta, Italy

3 SVeB - Department of Life Sciences and Biotechnology, University of Ferrara, Via L. Borsari 46, 44121 Ferrara, Italy 


\section{Introduction}

The evaporation from bare soil driven by the presence of shallow groundwater is a significant component of the hydrological balance in semi-arid and arid locations (Assouline et al. 2014; Quinn et al. 2018; Shokri et al. 2010), although it could be relevant also in temperate climate, particularly in the Mediterranean area (Balugani et al. 2017). Direct evaporation from open waters have been studied in detail (Harwell 2012), as well evapotranspiration from reference crops (Jensen and Allen 2016), but less studies have been developed so far on bare soil evaporation induced by shallow groundwater (Allen et al. 2005; Bittelli et al. 2008; Flammini et al. 2018). The evaporation rate is primarily influenced by the microclimatic condition present at a given site, like temperature, wind speed, solar radiation, relative humidity, etc... (Allen et al. 2005; Martens et al. 2017); and by the soil's physical properties, like texture (Lehmann et al. 2018), soil organic matter content and water table depth (Alkhaier et al. 2012; Assouline et al. 2014). Coarse texture soils are characterized by high capacity to deliver water to the evaporation surface, but limited capillary raise due to lack of silt and clay fractions (Quinn et al. 2018). In fact, the liquid flux is driven by the capillary pressure gradients that develops in the vadose zone and remains active until the capillary gradients are larger than the gravitational and viscous forces (Lehmann et al. 2008). Thus, in coarse texture soils the evaporation rate is largely affected by the water table depth. An increase of the evaporation rate is usually followed by a soil temperature decrease because of the energy loss as latent heat flux (Todd et al. 2000). Many studies on the interaction between liquid water movement, water vapor transfer, and heat flux have found that the movement of heat and soil moisture are coupled (Kurylyk et al. 2019). Although thermal gradients affect the redistribution of water in soils, the most important process, which determines the coupling between water and heat, is the transport of latent heat by vapor flux within the soil and at the interface between the soil and the atmosphere. The soil water and energy fluxes from the land surface have been investigated in detail (Hingerl et al. 2016; Jin et al. 2019; Larsen et al. 2016; Trevisan et al. 2020), but very few studies considered the influence of shallow groundwater on soil surface temperature and the entire vadose zone (Alkhaier et al. 2009; Alkhaier et al. 2012; Doble and Crosbie 2017; Kollet and Maxwell 2008). Although valuable findings have been captured from these studies, most of them focused on the relationship between groundwater and soil surface evaporation. This shows that the influence of shallow groundwater on the evaporation process and its related impact on the subsurface energy balance along a soil profile is still an active area of research as pointed out by Trautz et al. (2018). The latter highlighted the importance of intermediate-scale experimentation (1-10 m) against the use of column scale data to derive generalizations about bare soil evaporation dynamic upscaling. Therefore, this study was conducted using a large tank with representative scales and instrumentations employed in the field to quantify the spatial distribution of evaporation from shallow groundwater in sandy soils. As the authors are aware, this is the first study that elucidates via numerical modelling the spatial distribution of the evaporation rate from shallow groundwater in well controlled laboratory conditions. This study also investigates the influence of surface evaporation on evapoconcentration effect (increased solute concentration due to evaporation) in both the vadose and saturated zones. 


\section{Material and Methods}

\subsection{Experimental Set Up}

A large tank (1.4 m x $4.0 \mathrm{~m} \times 1.3 \mathrm{~m})$, assembled with an internal structure of armed PVC and fastened on an external structure of natural wood enforced by steel scaffolding pipes, was filled with coarse sand materials ( $\cong 9.0 \mathrm{~m}^{3}$ of sandy sediments and $\cong 0.5 \mathrm{~m}^{3}$ of gravel). The sediments were excavated from a sand pit located along a meander of the Aspio river alluvial plain (Ancona, Italy). The relatively homogeneous nature of the sedimentary succession consists of coarsening-upward sandy sediments. The sediments were transported at the Hydrogeological Laboratory of SIMAU Department (Università Politecnica delle Marche), poured into the tank starting from the inflow gravel wall toward the outflow wall and compacted by a large shovel. The tank was filled to a height of $1.1 \pm 0.02 \mathrm{~m}$. The natural compaction of sediment under saturated conditions was monitored for two months and after an initial localized collapse of $\cong 2.0 \mathrm{~cm}$ near the infiltration point the compaction was found to be negligible and the collapsed part refilled.

A constant head is present and can be applied to the tank via an external reservoir to create a steady state flux, but for this research was not used. The two gravel walls at the inflow and at the outflow were used to stabilize the groundwater flux (Giambastiani et al. 2013). The monitoring started in February 2020 and lasted for 4 months.

Eight piezometers with a bottom screen of $5 \mathrm{~cm}$ length and four fully screened wells were equipped with high resolution multi-level samplers (MLSs) and installed to form a semi-regular grid (Fig. 1). The wells were located along the central flowline of the tank and had an internal diameter (i.d.) of $5.0 \mathrm{~cm}$, while the piezometers located between the wells and the side walls of the tank had an i.d. of $2.0 \mathrm{~cm}$. Each MLS consisted of 6 HDPE tubes (4 mm i.d.) placed around the wells and piezometers, each HDPE tube was connected to a micro-screen of $0.5 \mathrm{~cm}$ length; the sampling ports were equally spaced every $10 \mathrm{~cm}$, from 5 to $65 \mathrm{~cm}$ from the tank bottom. The MLSs were sampled for salinity measurement only once at day 110 to minimize the perturbation of the ongoing experiment, collecting 20 $\mathrm{mL}$ in each saturated port in the central transect $\mathrm{C} 1, \mathrm{C} 2$ and $\mathrm{C} 3$ (Fig. 1). The groundwater heads, temperature and electrical conductivity were monitored every 10 minutes using a Soil \& Water Diver ${ }^{\circledR}$ water level data-logger (Eijkelkamp, Giesbeek, The Netherlands), corrected for atmospheric pressure changes via a Barologger ${ }^{\circledR}$ (Eijkelkamp, Giesbeek, The Netherlands) placed at the soil surface. The water level data resolution was $0.02 \%$ of the full scale and the accuracy was $\pm 0.05 \%$ of the full scale. Three $5 \mathrm{TE}^{\circledR}$ Meter probes (Meter Environment, Pullman, WA, USA) were installed inside the tank at 5, 20 and $40 \mathrm{~cm}$ below ground level (b.g.1.) to monitor volumetric water content (VWC), Temperature (T) and Soil Bulk Electrical Conductivity (ECb). Soil's ECb was converted in EC according to the model of Hilhorst (2000) and subsequently EC data were converted into salinity with standard conversion factors (APHA 2017). All probes were connected to a Meter data logger $\left(\mathrm{ECH}_{2} \mathrm{O}\right)$ recording every $10 \mathrm{~min}$.

Physical parameters (grain size, bulk density, porosity, etc...) were calculated via dry sieving and gravimetric measurements on 5 randomly collected samples see Supplementary Information (SI) Table S1. The saturated hydraulic conductivity (k) distribution was estimated by slug tests (Bouwer and Rice 1976), via the Kozeny-Carman formula (Carrier 2003) and via a constant rate pumping test. The direct estimation of evaporation from the water table was calculated using the White (1932), detailed information are reported in SI (Estimation of evaporation from groundwater). 

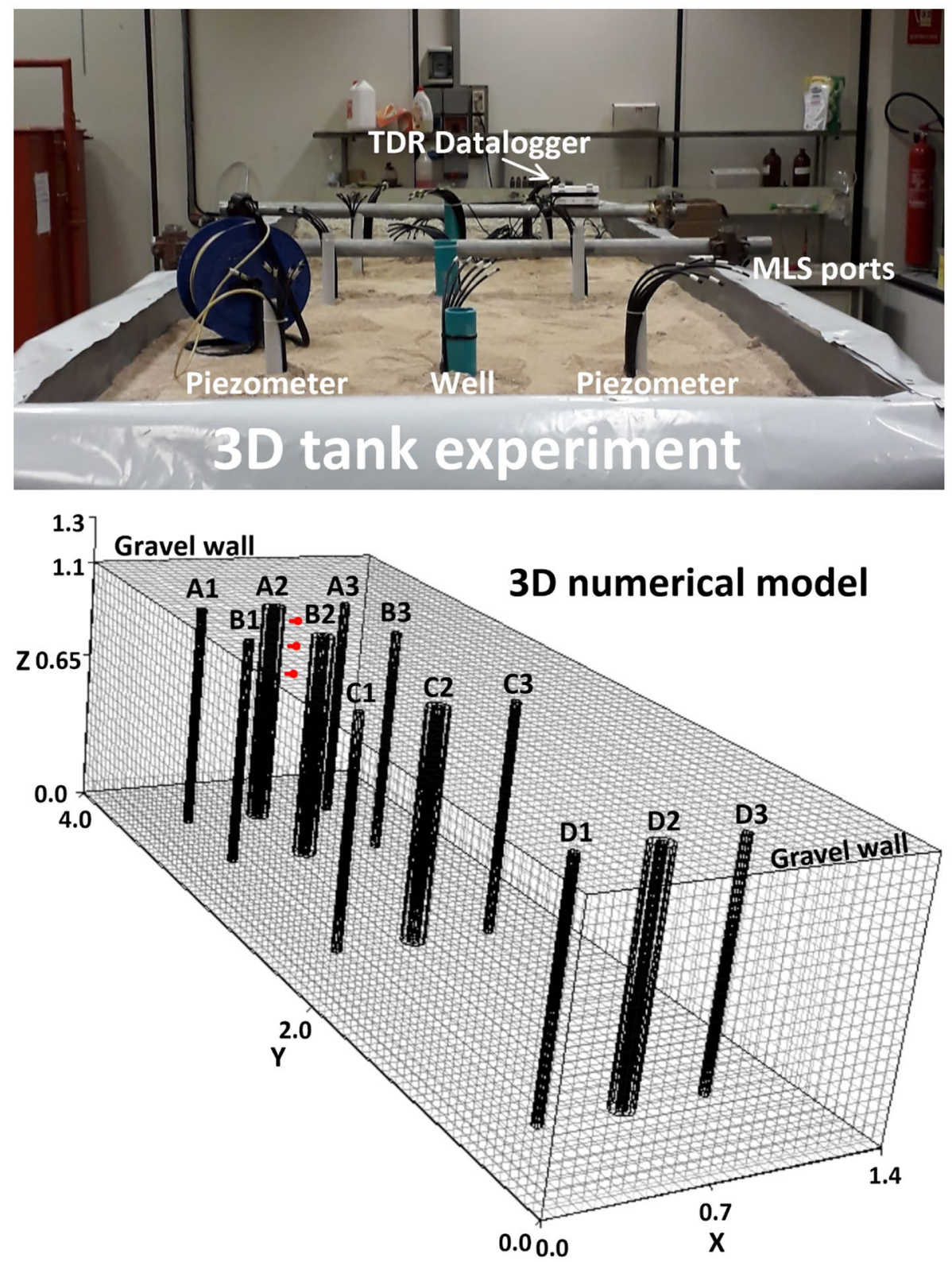

Fig. 1 Upper panel: picture of the tank experimental set up. Lower panel: tank numerical grid (grey), with the monitoring wells (A2, B2, C2, and D2) and piezometers. The location of 5TE probes (red marks) to monitor the unsaturated zone is also shown

\subsection{Numerical Model Set-Up}

Heat and solutes transport under variable density and viscosity can be simulated by SEAWAT Version 4.0 (Langevin et al. 2008), which couples MODFLOW-2005 (Harbaugh, 
2005) and MT3DMS (Zheng and Wang 1999) for simultaneous solution of flow and heat transport equations so that the effects of variable density can be considered.

To simulate the groundwater drawdown and the heat pulses created by the changes in atmospheric temperatures, a tridimensional transient state fully saturated SEAWAT model consisting of 80 rows, 28 columns and 22 layers was used to get a uniform cell size of $5 \mathrm{~cm}^{3}$.

Before to start the experiment, the constant rate pumping test $(4.01 / \mathrm{min}$ for $25 \mathrm{~min}$ utes) was analyzed via MODFLOW-2005 and PEST (Doherty 2010) by running a simulation with the Well package as sole boundary condition and using the Wetting factor to allow dry cells to be re-wetted once the pumping ceased. The automated inverse model PEST was used to obtain best estimates for the horizontal and vertical $\mathrm{k}$ values of the sand, the gravel walls and the average $S_{y}$ of the whole tank. The vertical $k$ values were tied to the horizontal ones to constrain parameters estimation; the objective function consisted of piezometric heads collected every minute, recorded from 11 observation piezometers and the pumping well (B2 in Fig. 1).

All the boundaries were set as no flow boundaries except for the upper most saturated layer that was set as the evaporation surface by using the Evapotranspiration package of SEAWAT. The latter is defined by a maximum evaporation rate and an extinction depth from the ground surface.

To simulate the dissolution of soluble salts and mineral phases like carbonates, the mass loading rate package of SEAWAT was employed. The water table was uniformly set at $0.50 \mathrm{~m}$ from the ground surface before the start of the experiment, while the small differences in groundwater salinity and temperature were interpolated and used as initial conditions. The time was discretized into 29 stress periods of 5 days each, this allowed to mimic the temperature variation recorded by the $5 \mathrm{TE}$ probe at $40 \mathrm{~cm}$ depth by setting the mean values over 5 days in the Time Variant Specified Concentration package of SEAWAT. Flow and transport parameters used for the simulations are listed reported in SI Table S2.

The Geometric Multigrid (GMG) was used as numerical solver for the groundwater flow and the third-order scheme Total Variations Diminishing ULTIMATE (TVD) was used to solve the advective term of the solute transport problem. Courant number was set to 0.1 to further minimize numerical dispersion.

The results obtained from the calibration procedure were evaluated computing different statistical indices. In the present study, the robustness of the applied methodology was defined by means of three indices: coefficient of determination $\left(\mathrm{R}^{2}\right)$, Nash-Sutcliffe efficiency (NSE) and percent of bias (PBIAS). According to Moriasi et al. (2007), the satisfactory thresholds of the three statistical indices for an acceptable streamflow simulation are $\mathrm{R}^{2} \geq 0.50, \mathrm{NSE} \geq 0.50$ and PBIAS $\pm 25 \%$.

\section{Results and Discussion}

\subsection{Unsaturated Zone Monitoring}

In the unsaturated zone, the VWC showed a slow decline at all the monitored depths until day 115 , where the topsoil started to desiccate more rapidly respect to the previous period (Fig. 2). The slow decline and not an abrupt one was imputable to the capillary rise forces, that provided a constant supply of water towards the evaporation surface, even if the sediment was a medium coarse sand. Congruently, the porewater salinity in 

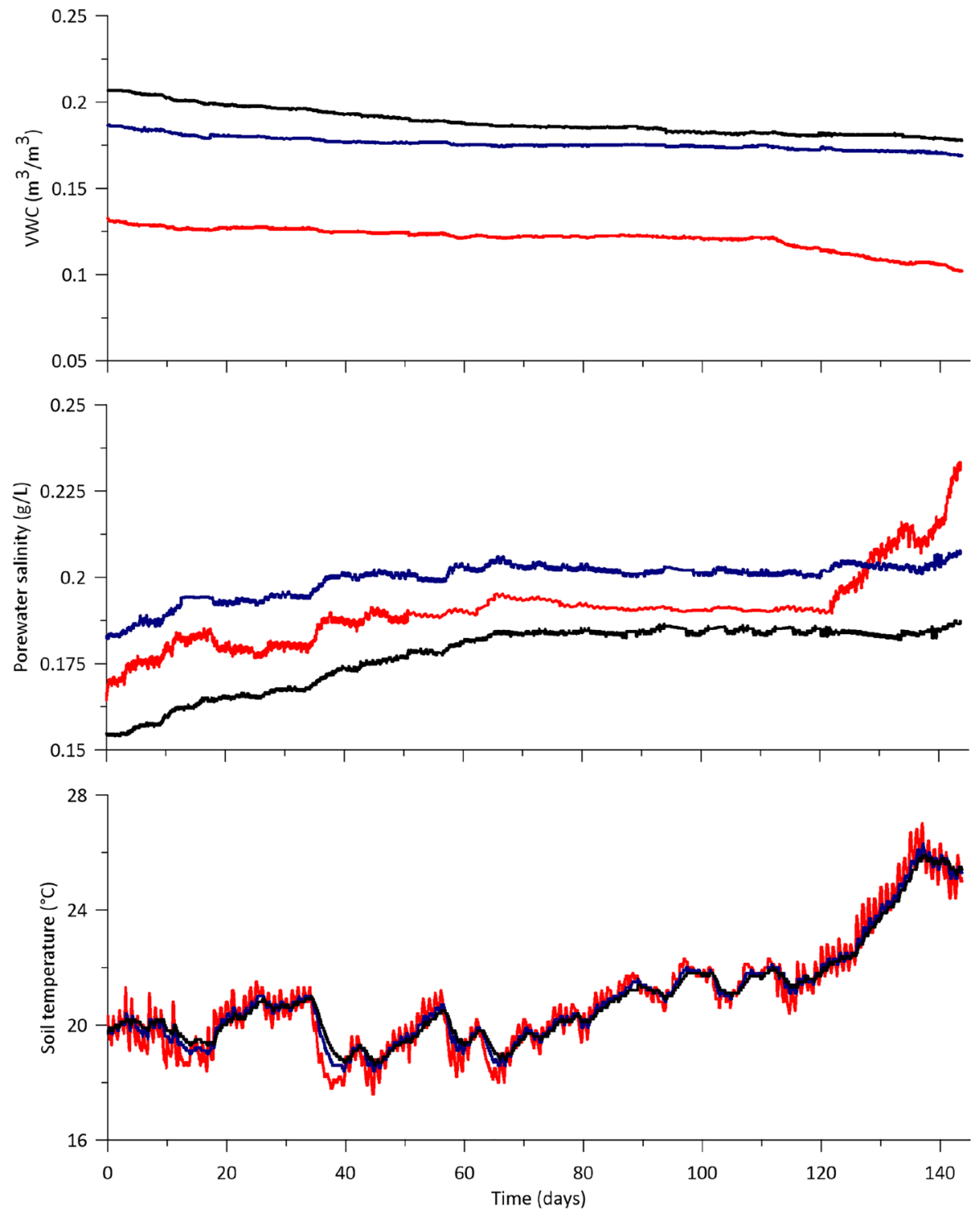

$5.0 \mathrm{~cm}$ b.g.I. $-20 \mathrm{~cm}$ b.g.I.

$40 \mathrm{~cm}$ b.g.l.

Fig. 2 Unsaturated zone continuous monitoring of VWC, porewater salinity and soil temperature

all the monitored ports increased due to the evapoconcentration process (Mastrocicco et al. 2019; Tanji 2002) although the salinity did not increase linearly, but after a rapid rise it stabilized after day 60 and increased abruptly after day 120 in the topsoil.

This behaviour agreed with the monitored soil temperature, which oscillated around $20 \pm 2{ }^{\circ} \mathrm{C}$ until day 60 then slowly increased until day 120 and rapidly until the end of 
the experiment. The vadose zone monitoring was pivotal to understand and simulate the evaporation from groundwater shown in the next chapter.

\subsection{K Field Characterization Via Inverse Modelling}

Figure 3 shows the results of the inverse modelling of the constant rate pumping test, here it can be seen that the model was able to fully capture the heads variation in
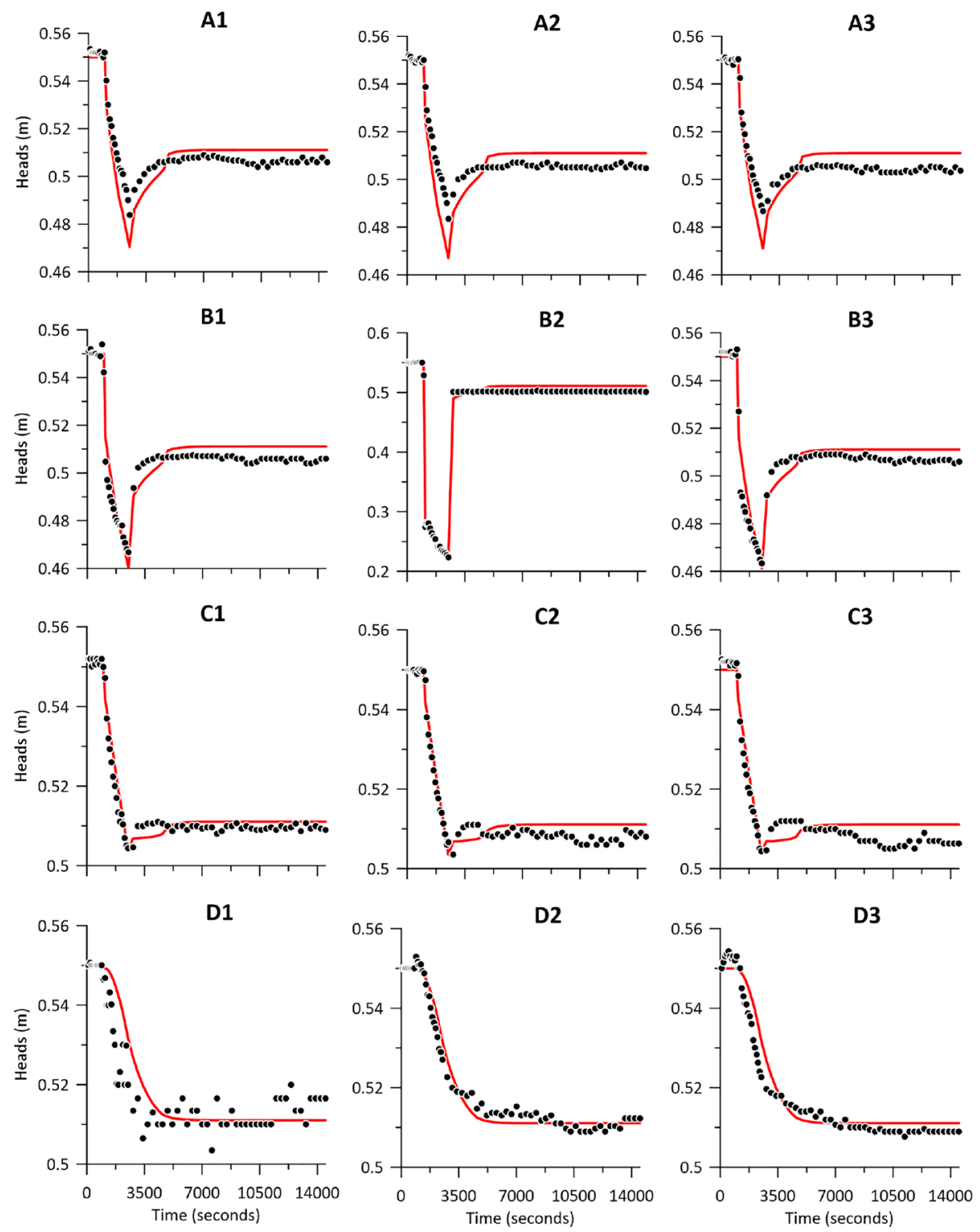

Fig. 3 Simulated hydraulic heads (red lines) and observed (black circles) in all the 12 monitoring points (1 per panel with their name in bold, refer to Fig. 1 for position) during the constant rate pumping test 
all the 12 monitoring points with a very low discrepancy between the observed and calculated values, exemplified by a $\mathrm{R}^{2}$ of 0.981 , a NSE of 0.98 and a PBIAS of only $0.08 \%$. Apart from small overestimations and underestimations of the hydraulic heads in A2, A3 and C3 the model was able to accurately reproduce the heads drawdown and recovery. Although, it can be noticed that D1 observations are more scattered than the other ones; this was due to the pressure transducer that was factory calibrated for heads variations from 1 to $100 \mathrm{~m}$ ( $1 \mathrm{~cm}$ resolution), while all the others had pressure transducers calibrated for heads variations from 1 to $10 \mathrm{~m}$, allowing a higher resolution $(0.2 \mathrm{~cm})$.

Table 1 shows the observed mean $\mathrm{k}$ values and the respective standard deviations for the slug tests, here a slightly lower value was retrieved and a relatively high standard deviation. This is normal since the slug tests provide information in the vicinity of the monitoring point (Giambastiani et al. 2013; Paradis et al. 2016) and usually the values are lower than the $\mathrm{k}$ values provided by pumping tests (Butler and Healey 1998). This could be due to small scale variations of $\mathrm{k}$ or to partial development of the monitoring wells, although in this case it was most likely due to the first reason since the wells were fully developed. Moreover, the Kozeni-Carman equation produced a very similar average $\mathrm{k}$ value with an even higher standard deviation, witnessing that small $\mathrm{k}$ variations are pronounced. Table 1 shows that the horizontal and vertical $\mathrm{k}$ values for both the gravel wall and the coarse medium sand in the tank are within the range of typical values for such textures (Fetter 2001). Also the $S_{y}$ is within typical values and was unified for both sand and gravel since initial sensitivity analyses provided little changes using distinct values. Nevertheless, the $S_{y}$ resulted the most sensitive parameter, followed by the horizontal $\mathrm{k}$ of the sand, while the horizontal $\mathrm{k}$ of the gravel wall and the specific storage $\left(\mathrm{S}_{\mathrm{s}}\right)$ were negligible. Vertical $\mathrm{k}$ parameters of sand and gravel were not considered in the sensitivity analysis since they were tied to horizontal $\mathrm{k}$ values.

From the hydraulic characterization of the tank the flow fundamental parameters were identified and employed to simulate the evaporation experiment.

\subsection{Saturated Zone Monitoring and Modelling Performance}

Figure 4 shows the observed and simulated trends of groundwater level, temperature, and salinity. The numerical model was able to capture the temperature variations even if the stress periods were set with a duration of 5 days; decreasing the stress period duration would allow to simulate more accurately the temperature variations during

Table 1 Horizontal k values retrieved from slug tests and Kozeni-Carman equation (K-C), standard deviation from 12 slug tests and for quintuplicate samples for Kozeni-Carman equation. Calibrated model parameters with their composite parameter sensitivities calculated via PEST

\begin{tabular}{lccclcl}
\hline Parameter & $\begin{array}{l}\text { Measured via } \\
\text { slug tests }\end{array}$ & $\begin{array}{l}\text { Measured } \\
\text { via K-C }\end{array}$ & $\begin{array}{l}\text { Modelled } \\
\text { sand tank }\end{array}$ & Sensitivity & $\begin{array}{l}\text { Modelled } \\
\text { gravel wall }\end{array}$ & Sensitivity \\
\hline Horizontal k (m/d) & $34.5 \pm 28.1$ & $42.3 \pm 40.6$ & 60.1 & $3.4 \mathrm{e}^{-3}$ & 659.4 & $4.5 \mathrm{e}^{-5}$ \\
Vertical k $(\mathrm{m} / \mathrm{d})$ & - & - & 30.0 & - & 329.7 & - \\
$\mathrm{S}_{\mathrm{s}}(1 / \mathrm{m})$ & - & - & $1.0 \mathrm{e}^{-4}$ & $1.2 \mathrm{e}^{-6}$ & $1.0 \mathrm{e}^{-4}$ & $1.1 \mathrm{e}^{-6}$ \\
$\mathrm{~S}_{\mathrm{y}}(-)$ & - & - & 0.226 & $8.2 \mathrm{e}^{-3}$ & 0.226 & $8.2 \mathrm{e}^{-3}$ \\
\hline
\end{tabular}



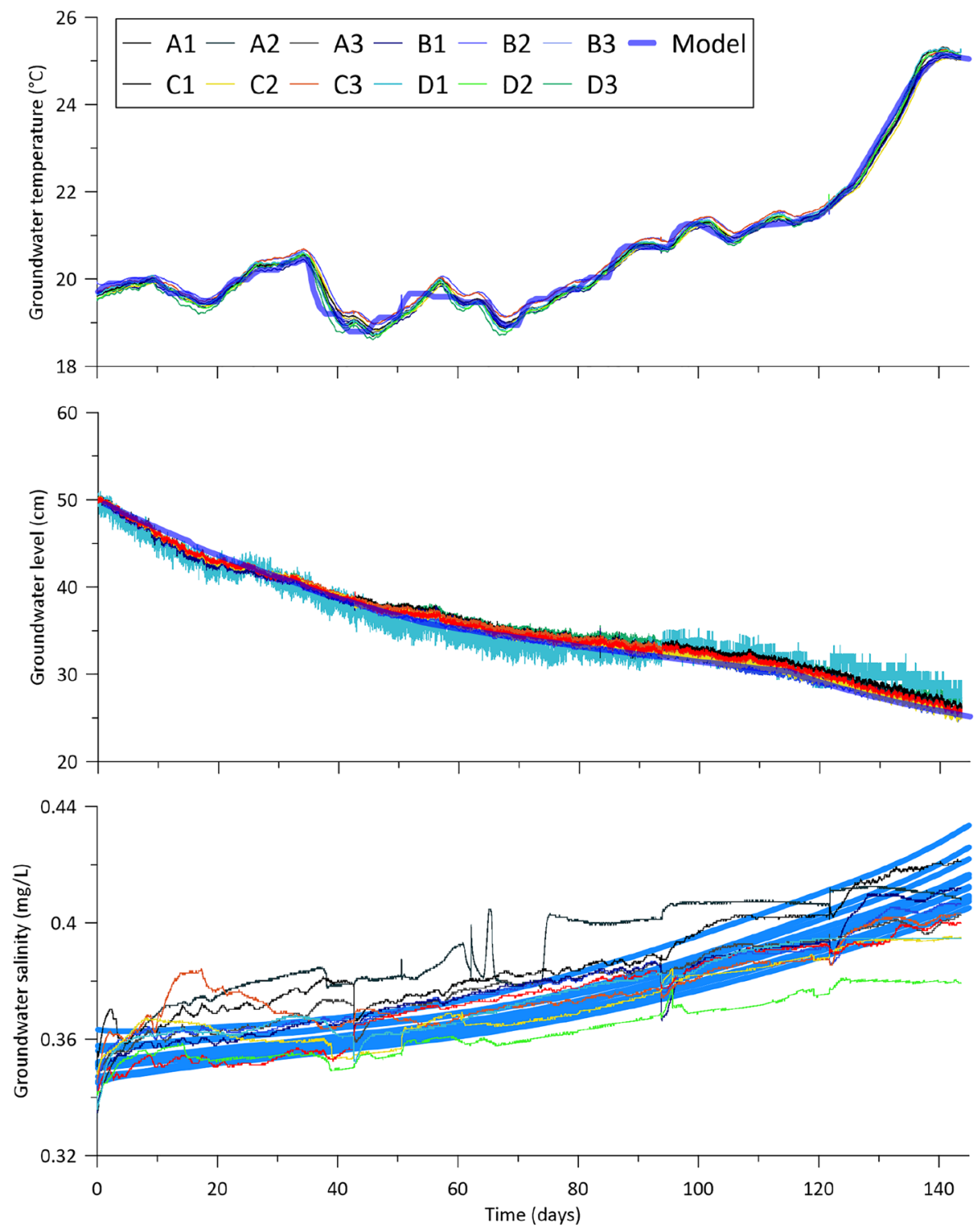

Fig. 4 Saturated zone continuous monitoring of groundwater temperature, level, and salinity in the 4 monitoring wells and 8 piezometers; modelled values are also shown for comparison

the experiment. Although, the model performance was considered satisfactory even using such a time discretization (Table 2), with all the three performance indicators well above the minimal requirement defined by Moriasi et al. (2007). It must be noticed that even if the initial temperature distribution was non-homogeneous, the 
Table 2 Model performance indicators for groundwater temperature (T), level (GWL), and salinity (upper part). Calibrated flow and solute transport model parameters (lower part)

\begin{tabular}{llcc}
\hline Model performance indicators & $\mathrm{T}$ & GWL & Salinity \\
\hline $\mathrm{R}^{2}(-)$ & 0.972 & 0.981 & 0.854 \\
NSE (-) & 0.970 & 0.985 & 0.794 \\
PBIAS (\%) & -0.82 & 0.51 & -4.89 \\
Model Parameter & & & 2.3 \\
Maximum evaporation rate $1^{\text {st }}$ period $(\mathrm{mm} / \mathrm{d})$ & & 1.5 \\
Maximum evaporation rate $2^{\text {nd }}$ period $(\mathrm{mm} / \mathrm{d})$ & & 4.4 \\
Maximum evaporation rate $3^{\text {rd }}$ period $(\mathrm{mm} / \mathrm{d})$ & & 0.90 \\
Extinction depth $(\mathrm{m})$ & & & 0.35 \\
Evaporation concentration $(\mathrm{g} / \mathrm{L})$ & & $5.0 \mathrm{e}^{-9}$ \\
Mass loading rate $(\mathrm{g} / \mathrm{d})$ & & & \\
\hline
\end{tabular}

time variant imposed temperature at the water table was set constant for the whole tank and this generated a nearly uniform temperature distribution in the numerical model (Fig. 4).

This was also evident for the calculated heads, that were driven by the evaporation rate (the only stress set to the groundwater flow component of the model). This, however, was not held constant for the whole period, since after a few trials it was impossible to calibrate the model given the change in slope of groundwater drawdown recorded from day 115 (Fig. 4). Thus, the evaporation rate was split into 3 stress periods, the first from day 0 to day 60 , the second from 61 to 120 and the third one from 121 till the end of the simulation, as identified by the vadose zone monitoring. The calibrated maximum evaporation rates and the extinction depth are reported in Table 2 (lower part). The rates are consistent with literature data on evaporation from bare soils in temperate climates (Aydin et al. 2008; Bittelli et al. 2008). Although the evaporation rates estimated via the White's method (see SI Fig. S1) were much lower than the surface evaporation rates and found to be similar to field observed values recorded in semi-arid climates (Gong et al. 2020).

Surprisingly, the extinction depth found in this study, $0.90 \mathrm{~m} \mathrm{b.g.l.} \mathrm{is} \mathrm{higher} \mathrm{than}$ usually found in literature. In fact, Mansell and Hussey (2005) showed that when the water table is at $0.60 \mathrm{~m}$ b.g.l., evaporation from coarse and medium sands was approximately $10 \%$ of the evaporation from surface waters. The same conclusions were reached by Neal (2012). A review of the extinction depth values in response of soil texture and land cover was proposed by Shah et al. (2007) where for sandy soils they proposed the value of $0.50 \pm 0.05 \mathrm{~m}$.

The model performance was very satisfying (Table 2 upper part) for groundwater level and temperature but the same was not true for salinity, which displayed lower values of both $\mathrm{R}^{2}$ and NSE. This was likely due to the long screens of the monitoring wells that promoted artificial mixing (McMillan et al. 2014).

Besides, the evapoconcentration alone was not sufficient to describe and quantify the observed salinity increase, in fact without the minerals and salts dissolution, here 


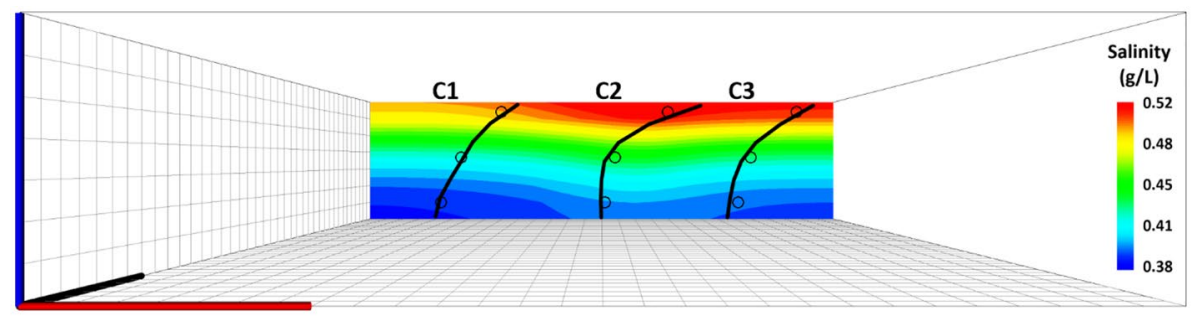

Fig. 5 Model results showing salinity contour cropped at C1-C2-C3 plane in day 110. Modelled concentrations and observed salinities are also shown for comparison

accounted for with the mass loading rate, rather poor model performance indicators were obtained for salinity (not shown). The best model performance was obtained via trial and error and the values are reported in the lower part of Table 2.

Figure 5 reported the concentration profile of calculated salinity at day 110 when the central MLSs (C1, C2 and C3) were sampled. An appreciable salinity gradient developed in all the MLSs although the groundwater was still fresh. Nevertheless, this proves that the increase in salinity observed with the continuous monitoring was essentially due to evapoconcentration processes and not due to salt and mineral phases dissolution. Moreover, this well explain the sudden salinity variations observed in the fully screened monitoring wells that could have been caused by small convective cells that often develop in open tube wells, induced by temperature gradients (Colombani et al. 2016; McHugh et al. 2012).

Given that the transport parameters are the most uncertain in this model (Table 2 lower part), a single parameter sensitivity analysis has been performed on the most critical ones, namely: dispersivity, mass loading rate and effective porosity.

\subsection{Sensitivity Analysis}

The dispersivity and mass loading rate were doubled and halved, while the effective porosity was increased or decreased of $10 \%$ to be consistent with the physically based values of this parameter (Fetter 2001). The results are shown in Fig. 6, here it is evident that the dispersivity did not affect appreciably the calculated salinity. While the mass loading rate, which resembles the minerals dissolution rate, moderately effected the calculated salinity especially in the scenario with $100 \%$ increase respect to the calibrated value, producing a general increase of approximately $50 \mathrm{mg} / \mathrm{l}$ at the end of the simulation. Finally, the effective porosity resulted to be the most influencing parameter, with calculated salinities that in some monitoring wells were nearly doubled in the scenario with the highest plausible value $(0.22)$; or calculated salinities that did not vary during the simulation in the scenario with the lowest plausible value (0.18). 


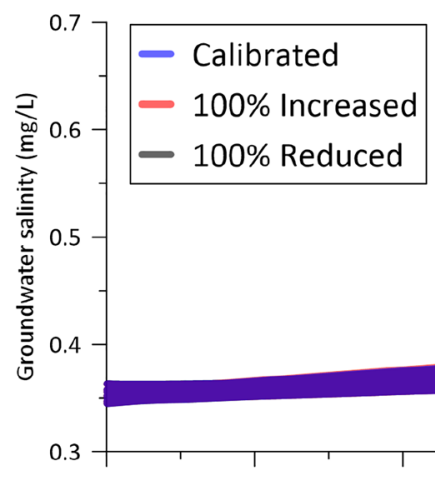

\section{Dispersivity}
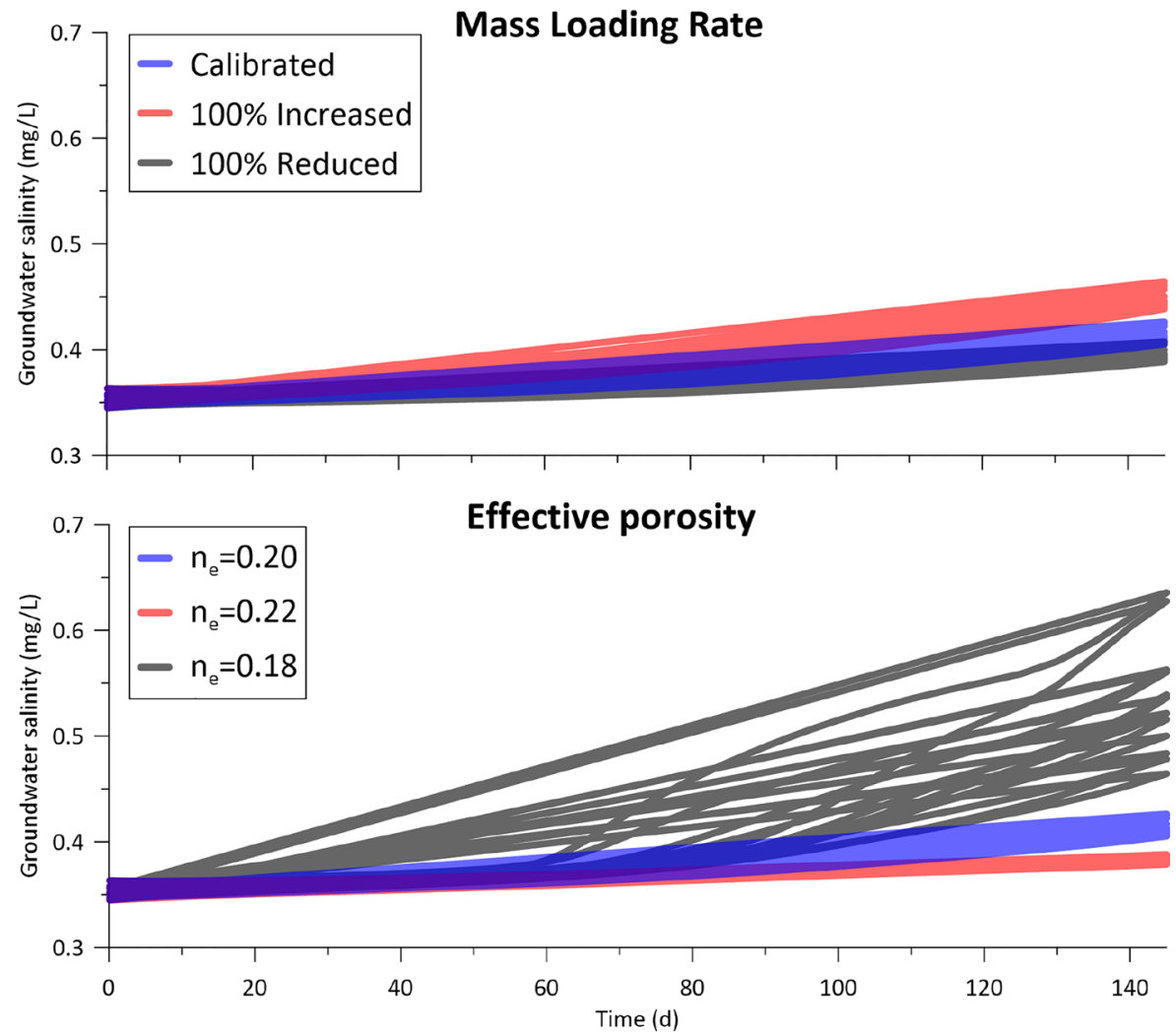

Fig. 6 Salinity in the 4 monitoring wells and 8 piezometers for the calibrated model (blue lines) and in both the increased (red lines) and reduced (black lines) model scenarios

\section{Conclusions}

This study shows that evaporation from coarse medium sands can be relevant in temperate environments if the water table is near to the ground surface $(0.5-1.0 \mathrm{~m})$, with a measured extinction depth $(0.9 \mathrm{~m})$ higher than the ones proposed by previous 
studies with sandy sediments. This has also implications for laboratory experiments, like column or tank experiments, where this important parameter is often unaccounted. Moreover, the monitoring data showed that groundwater temperatures and levels were homogeneously distributed over the monitoring network and their behavior could be approximated using a one-dimensional approach, treating the whole tank as a homogeneous soil column. Despite the relatively homogeneous drawdown, the White's method used to calculate the daily evaporation rate from the water table produced values affected by large spatial variability. This, in conjunction with small differences in the initial concentrations, determined appreciable changes in the evapoconcentration process that were well captured only using a three-dimensional flow and transport model. The sensitivity analysis showed that small changes in the effective porosity could lead to very different concentrations' distribution during the evapoconcentration process, thus the influence of this parameter should be carefully characterized in future studies. This study demonstrates that shallow groundwater evaporation from sandy soils can produce homogeneous water table drawdown but appreciable differences in groundwater salinity at the meso-scale and to accurately capture such variations high resolution multi-level samplers must be employed.

Supplementary Information The online version contains supplementary material available at https://doi. org/10.1007/s11269-021-02896-2.

Author Contributions Nicolò Colombani: model conceptualization, methodology, data curation, writing original draft; Davide Fronzi: validation, data curation; Stefano Palpacelli: validation, data curation; Mattia Gaiolini: visualization, software, formal analysis; Maria Pia Gervasio: formal analysis; Mirco Marcellini: data curation; Micòl Mastrocicco: writing - review and editing, methodology; Alberto Tazioli: supervision, methodology.

Funding Open access funding provided by Università degli Studi della Campania Luigi Vanvitelli within the CRUI-CARE Agreement. This research received no external funding.

Availability of Data and Material Data are available from the corresponding author upon request.

Code Availability Available upon reasonable request.

\section{Declarations}

Conflicts of Interest The authors declare no conflict of interest.

Open Access This article is licensed under a Creative Commons Attribution 4.0 International License, which permits use, sharing, adaptation, distribution and reproduction in any medium or format, as long as you give appropriate credit to the original author(s) and the source, provide a link to the Creative Commons licence, and indicate if changes were made. The images or other third party material in this article are included in the article's Creative Commons licence, unless indicated otherwise in a credit line to the material. If material is not included in the article's Creative Commons licence and your intended use is not permitted by statutory regulation or exceeds the permitted use, you will need to obtain permission directly from the copyright holder. To view a copy of this licence, visit http://creativecommons.org/licenses/by/4.0/.

\section{References}

Alkhaier F, Flerchinger GN, Su Z (2012) Shallow groundwater effect on land surface temperature and surface energy balance under bare soil conditions: modeling and description. Hydrol Earth Syst Sci 16:1817-1831. https://doi.org/10.5194/hess-16-1817-2012 
Alkhaier F, Schotting RJ, Su Z (2009) A qualitative description of shallow groundwater effect on surface temperature of bare soil. Hydrol Earth Syst Sci 13:1749-1756. https://doi.org/10.5194/hess-13-1749-2009

Allen RG, Pereira LS, Smith M, Raes D, Wright JL (2005) FAO-56 Dual Crop Coefficient Method for Estimating Evaporation from Soil and Application Extensions. J Irrig Drain Eng 131:2-13. https://doi.org/ 10.1061/(ASCE)0733-9437(2005)131:1(2)

American Public Health Association (APHA) (2017) Standard Methods for the Examination of Water and Wastewater. 23rd edition. American Public Health Association, American Water Works Association, and Water Environment Federation, Washington DC (1268 pp. ISBN: 978-0-87553-287-5)

Assouline S, Narkis K, Gherabli R, Lefort P, Prat M (2014) Analysis of the impact of surface layer properties on evaporation from porous systems using column experiments and modified definition of characteristic length. Water Resour Res 50:3933-3955. https://doi.org/10.1002/2013WR014489

Aydin M, Yano T, Evrendilek F, Uygur V (2008) Implications of climate change for evaporation from bare soils in a Mediterranean environment. Environ Monit Assess 140:123-130. https://doi.org/10.1007/ s10661-007-9854-4

Balugani E, Lubczynski MW, Reyes-Acosta L, van der Tol C, Francés AP, Metselaar K (2017) Groundwater and unsaturated zone evaporation and transpiration in a semi-arid open woodland. J Hydrol 547:54-66. https://doi.org/10.1016/j.jhydrol.2017.01.042

Bittelli M, Ventura F, Campbell GS, Snyder RL, Gallegati F, Pisa PR (2008) Coupling of heat, water vapor, and liquid water fluxes to compute evaporation in bare soils. J Hydrol 362:191-205. https://doi.org/10. 1016/j.jhydrol.2008.08.014

Bouwer H, Rice RC (1976) A slug test for determining hydraulic conductivity of unconfined aquifers with completely or partially penetrating wells. Water Resour Res 12:423-428. https://doi.org/10.1029/ WR012i003p00423

Butler JJ, Healey JM (1998) Relationship Between Pumping-Test and Slug-Test Parameters: Scale Effect or Artifact? Ground Water 36:305-312. https://doi.org/10.1111/j.1745-6584.1998.tb01096.x

Carrier WD (2003) Goodbye, Hazen; Hello, Kozeny-Carman. J Geotech Geoenviron Eng 129:1054-1056. https://doi.org/10.1061/(ASCE)1090-0241(2003)129:11(1054)

Colombani N, Giambastiani BMS, Mastrocicco M (2016) Use of shallow groundwater temperature profiles to infer climate and land use change: interpretation and measurement challenges. Hydrol Process 30:2512-2524. https://doi.org/10.1002/hyp.10805

Doble RC, Crosbie RS (2017) Review: Current and emerging methods for catchment-scale modelling of recharge and evapotranspiration from shallow groundwater. Hydrogeol J 25:3-23. https://doi.org/ 10.1007/s10040-016-1470-3

Doherty J (2010) PEST - Model-independent parameter estimation. Version 12. Watermark Computing. Australia. Downloaded from http://www.pesthomepage.org/

Fetter CW (2001) Applied hydrogeology, 4th edn. Waveland Press Inc., Long Grove, IL

Flammini A, Corradini C, Morbidelli R, Saltalippi C, Picciafuoco T, Giráldez JV (2018) Experimental analyses of the evaporation dynamics in bare soils under natural conditions. Water Resour Manage 32(3):1153-1166. https://doi.org/10.1007/s11269-017-1860-х

Giambastiani BMS, Colombani N, Mastrocicco M (2013) Limitation of using heat as a groundwater tracer to define aquifer properties: experiment in a large tank model. Environ Earth Sci 70:719728. https://doi.org/10.1007/s12665-012-2157-2

Gong C, Wang W, Zhang Z, Wang H, Luo J, Brunner P (2020) Comparison of field methods for estimating evaporation from bare soil using lysimeters in a semi-arid area. J Hydrol 590:125334. https:// doi.org/10.1016/j.jhydrol.2020.125334

Harbaugh AW (2005) MODFLOW-2005, the U.S. Geological Survey modular groundwater model - the Ground-Water Flow Process: U.S. Geol Surv Tech Method 6-A16. https://doi.org/10.3133/tm6A16

Harwell GR (2012) Estimation of evaporation from open water-a review of selected studies. USGS Sci Investig Rep 2012-5202. https://pubs.er.usgs.gov/

Hilhorst MA (2000) A Pore Water Conductivity Sensor. Soil Sci Soc Am J 64:1922-1925. https://doi. org/10.2136/sssaj2000.6461922x

Hingerl L, Kunstmann H, Wagner S, Mauder M, Bliefernicht J, Rigon R (2016) Spatio-temporal variability of water and energy fluxes - a case study for a mesoscale catchment in pre-alpine environment. Hydrol Process 30:3804-3823. https://doi.org/10.1002/hyp.10893

Jensen ME, Allen RG (Eds.) (2016) Evaporation, Evapotranspiration, and Irrigation Water Requirements. Am Soc Civil Eng Reston VA. https://doi.org/10.1061/9780784414057

Jin J, Wang Q, Wang J, Otieno D (2019) Tracing water and energy fluxes and reflectance in an arid ecosystem using the integrated model SCOPE. J Environ Manag 231:1082-1090. https://doi.org/10. 1016/j.jenvman.2018.10.090 
Kollet SJ, Maxwell RM (2008) Capturing the influence of groundwater dynamics on land surface processes using an integrated, distributed watershed model. Water Resour Res 44. https://doi.org/10. 1029/2007WR006004

Kurylyk BL, Irvine DJ, Bense VF (2019) Theory, tools, and multidisciplinary applications for tracing groundwater fluxes from temperature profiles. Wiley Interdiscip. Rev Water 6:e1329. https://doi. org/10.1002/wat2.1329

Langevin CD, Thorne Jr DT, Dausman AM, Sukop MC, Guo W (2008) SEAWAT version 4: a computer program for simulation of multi-species solute and heat transport. Tech Method Book 6 Chap A22 USGS. https://doi.org/10.3133/tm6A22

Larsen MAD, Refsgaard JC, Jensen KH, Butts MB, Stisen S, Mollerup M (2016) Calibration of a distributed hydrology and land surface model using energy flux measurements. Agric For Meteorol 217:74-88. https://doi.org/10.1016/j.agrformet.2015.11.012

Lehmann P, Assouline S, Or D (2008) Characteristic lengths affecting evaporative drying of porous media. Phys Rev E 77:056309. https://doi.org/10.1103/PhysRevE.77.056309

Lehmann P, Merlin O, Gentine P, Or D (2018) Soil Texture Effects on Surface Resistance to Bare-Soil Evaporation. Geophys. Res Lett 45:10398-10405. https://doi.org/10.1029/2018GL078803

Mansell MG, Hussey SW (2005) An investigation of flows and losses within the alluvial sands of ephemeral rivers in Zimbabwe. J Hydrol 314:192-203. https://doi.org/10.1016/j.jhydrol.2005.03.015

Martens B, Miralles DG, Lievens H, van der Schalie R, de Jeu RAM, Fernández-Prieto D, Beck HE, Dorigo WA, Verhoest NEC (2017) GLEAM v3: satellite-based land evaporation and root-zone soil moisture. Geosci Model Dev 10:1903-1925. https://doi.org/10.5194/gmd-10-1903-2017

Mastrocicco M, Busico G, Colombani N, Vigliotti M, Ruberti D (2019) Modelling actual and future seawater intrusion in the Variconi coastal wetland (Italy) due to climate and landscape changes. Water 11:1502. https://doi.org/10.3390/w11071502

McHugh TE, Newell CJ, Landazuri RC, Molofsky LJ, Adamson DT (2012) The influence of seasonal vertical temperature gradients on no-purge sampling of wells. Remediat J 22:21-36. https://doi.org/ 10.1002/rem. 21328

McMillan LA, Rivett MO, Tellam JH, Dumble P, Sharp H (2014) Influence of vertical flows in wells on groundwater sampling. J Contam Hydrol 169:50-61. https://doi.org/10.1016/j.jconhyd.2014.05.005

Moriasi DN, Arnold JG, Van Liew MW, Bingner RL, Harmel RD, Veith TL (2007) Model Evaluation Guidelines for Systematic Quantification of Accuracy in Watershed Simulations. Trans ASABE 50:885-900. https://doi.org/10.13031/2013.23153

Neal I (2012) The potential of sand dam road crossings. Dams Reserv 22:129-143. https://doi.org/10.1680/ dare.13.00004

Paradis D, Lefebvre R, Gloaguen E, Giroux B (2016) Comparison of slug and pumping tests for hydraulic tomography experiments: a practical perspective. Environ Earth Sci 75:1159. https://doi.org/10.1007/ s12665-016-5935-4

Quinn R, Parker A, Rushton K (2018) Evaporation from bare soil: Lysimeter experiments in sand dams interpreted using conceptual and numerical models. J Hydrol 564:909-915. https://doi.org/10.1016/j. jhydrol.2018.07.011

Shah N, Nachabe M, Ross M (2007) Extinction depth and evapotranspiration from ground water under selected land covers. Groundwater 45(3):329-338. https://doi.org/10.1111/j.1745-6584.2007.00302.x

Shokri N, Lehmann P, Or D (2010) Evaporation from layered porous media. J Geophys Res 115:B06204. https://doi.org/10.1029/2009JB006743

Tanji KK (2002) Salinity in the Soil Environment, in: Salinity: Environment - Plants - Molecules. Kluwer Academic Publishers, Dordrecht 21-51. https://doi.org/10.1007/0-306-48155-3_2

Todd R (2000) The Bowen ratio-energy balance method for estimating latent heat flux of irrigated alfalfa evaluated in a semi-arid, advective environment. Agric For Meteorol 103:335-348. https://doi.org/10. 1016/S0168-1923(00)00139-8

Trautz AC, Illangasekare TH, Howington S (2018) Experimental testing scale considerations for the investigation of bare-soil evaporation dynamics in the presence of sustained above-ground airflow. Water Resour Res 54(11):8963-8982. https://doi.org/10.1029/2018WR023102

Trevisan A, Venema V, Kollet S, Rahman M (2020) The topographic control on land surface energy fluxes: A statistical approach to bias correction. J Hydrol 584:124669. https://doi.org/10.1016/j.jhydrol.2020.124669

White WN (1932) Method of estimating groundwater supplies based on discharge by plants and evaporation from soil - Results of investigation in Escalante valley. Tech Rep Utah US Geol Surv Water Supply Paper 659-A 
Zheng C, Wang PP (1999) MT3DMS: A modular three-dimensional multispecies model for simulation of advection, dispersion and chemical reactions of contaminants in groundwater systems; Documentation and Users Guide, Contract Report SERDP-99-1, U.S. Army Eng Res Dev Center Vicksburg MS

Publisher's Note Springer Nature remains neutral with regard to jurisdictional claims in published maps and institutional affiliations. 